\title{
El poder y la gerencia en las organizaciones "un análisis crítico sobre la diversidad de su concepción"**
}

\author{
Bustamante Uzcátegui, Suleima ** \\ Pérez de Maldonado, Isabel *** \\ Maldonado Pérez, Marisabel ****
}

\section{Resumen}

En este estudio se realiza el análisis del poder, la diversidad filosófica de su concepción y, su aplicabilidad de uso en la gerencia de las organizaciones como forma de construir una referencia teórica-metodológica. Es una investigación de tipo documental apoyada en la hermenéutica, una vez que se hace la interpretación analítica de escritos sobre el tema. Se reconoce que el dominio en las organizaciones por quiénes ostentan el poder, está implícito en la burocracia que las caracteriza. La discusión revela la predominancia por el posicionamiento político, social y económico como vía para obtener el poder; así también la relevancia del liderazgo, la comunicación y la confianza, como inductores de la productividad organizacional.

Palabras clave: Poder, gerencia, organizaciones, diversidad filosófica.

\section{Power and Management in Organizations "A Critical Analysis of the Diversity of its Conception"}

\section{Abstract}

This study analyzes power, the philosophical diversity of its conception and its applicability to managing organizations as a way to construct a theoretical-methodological reference. The research

Recibido: 23-01-07. Aceptado: 15-07-07

* Este estudio es un reporte de los proyectos que desarrolla la Línea de Comportamiento Organizacional y Productividad, adscrita al Núcleo de Investigación en Comportamiento Organizacional. UPEL-IPB.

** Profesora Titular UPEL. PPI. Nivel I. Vicerrectorado de Docencia- UPEL-Caracas, Venezuela. E-mail: suleimabu@cantv.net

*** Profesora Titular UPEL-IPB. PPI Nivel II. Coordinadora del Núcleo de Investigación en Comportamiento Organizacional. UPEL-IPB. E-mail: isabelpdm@cantv.net

**** Profesora Instructor Ing. Industrial. PPI. Nivel Candidato. Adscrita al Dpto. de Educación Técnica UPEL-IPB. E-mail: marisabelmp@hotmail.com 
El poder y la gerencia en las organizaciones

Bustamante U., Suleima; Pérez de M., Isabel y Maldonado P., Marisabel

is of a documentary type supported by hermeneutics, once the analytical interpretation of writings on the subject begins. It is recognized that control in organizations by those who show power is implicit in the bureaucracy that characterizes them. The discussion reveals predominance by political, social and economic positioning as a way to obtain power, as well as the relevance of leadership, communication and confidence as inducers of organizational productivity.

Key words: Power, management, organizations, philosophical diversity.

\section{Introducción}

El clima de incertidumbre política, social y económica que afecta a los distintos sectores que conforman la sociedad mundial, despierta el interés por revisar la predominancia por el posicionamiento político, social y económico como vía para obtener el poder y los beneficios que de él se generan, en tanto aparece la dominación como la aptitud o la capacidad de coacción basada en la fuerza, que es la otra parte intrínseca del poder.

El análisis de cómo esta situación afecta las organizaciones y en especial su aplicabilidad de uso, lleva a las autoras de este trabajo a discutir algunas concepciones filosóficas del poder como una fuerza inherente a todas las formas de vida en las organizaciones; la sociedad acentúa cada vez más su carácter organizacional, nacemos dentro de las organizaciones, somos preparados por ellas y la mayor parte de nosotros laboramos en ellas; de modo que, ésta es definida como una unidad social o agrupación humana de mayor o menor tamaño, constituida para alcanzar determinados fines y objetivos. En el nuevo ordenamiento social, el poder es una combinación de recursos humanos con medios materiales y técnicos para alcanzar fines específicos, y donde éste se comporta como una fuerza determinante en la medida que es utilizado para obtener manifiesto futuro.
La discusión gira en torno a algunas conceptualizaciones sobre el poder apoyada en tres aspectos: a) La naturaleza social del hombre; b) su indigencia individual; y c) la satisfacción de sus necesidades para el mejoramiento de su calidad de vida, en beneficio de la productividad del grupo y de la sociedad en la cual conviven. En el primer aspecto se puede destacar que la concepción universalmente más admitida, es que el hombre como ser individual de naturaleza social, como individuo, está compuesto inseparablemente de materialidad y espiritualidad. Como ser social, precisa de los demás seres para satisfacer sus necesidades para poder sobrevivir; es a partir de esta necesidad social que surge en el hombre la exigencia a la organización, en consecuencia los seres humanos crean organizaciones para satisfacer requerimientos, lograr fines y objetivos y mejorar la calidad de vida y su interacción para la productividad. De manera que estudiar el poder, nos lleva a realizar una revisióncritica como soporte teórico-metodológico para su análisis, en tanto se identifican los mecanismos, las relaciones, los efectos, los tipos y las generalidades; análisis que se fundamenta en la diversidad filosófica de su concepción y que constituye el preámbulo teórico para conocer un poco mas sobre su actuar en la gerencia de las organizaciones. 


\section{El poder y la diversidad filosófica de su concepción}

La presencia de un momento histórico caracterizado por las grandes transformaciones y un nuevo ordenamiento social que generan en las sociedades y en especial en el aparato del Estado, donde también están presentes algunos procesos de ruptura y de mutaciones producto del mundo globalizado, hace necesaria la consideración de las distintas denominaciones de Estado. Para unos el Estado es el interesado en el bienestar, para otros se le ha denominado estado de partidos en cuanto a que el actor o el sujeto real del poder estatal son los mismos partidos, y otros hacen referencia al estado de asociaciones en cuanto a que las decisiones estatales están por los grupos de intereses organizados, todas estas denominaciones hacen alusión a la distribución del poder.

Es así que aparece la denominación de Estado social, que es el intento de adaptación del Estado tradicional a las condiciones sociales de la civilización industrial y post industrial con sus complejidades, pero también con sus grandes posibilidades técnicas, económicas y organizativas para enfrentarlos (García-Pelayo, 1987).

Así mismo en los últimos tiempos está adquiriendo vital importancia las temáticas relacionadas a la globalización, el poder local, la participación ciudadana y la sistemática disminución del papel del Estado; de modo que, estamos ante una coyuntura de cambios en la administración tradicional del Estado caracterizada por ser centralizada, burocrática, autoritaria, monocultural y excluyente, orienta- da a una administración pública más democrática, participativa, y con menos intervención del Estado. Esta nueva forma de administración estatal, discutida en distintos niveles, necesariamente conduce a una nueva concepción de sus funciones, sus políticas y sus relaciones con la sociedad en general, donde la participación ciudadana ejerce un papel importante en aspectos, tales como el control y la auditoria social.

El poder está implícito como una forma inherente a la persona humana, a las instituciones sociales y políticas, donde cada uno de ellos se convierte en los agentes más inmediatos para la búsqueda de la rearticulación del tejido social. En fin, nos encontramos a las puertas de un nuevo estadio, donde las fuerzas económicas, la tecnología, el medio ambiente, las políticas sociales, están llamadas a ser reestructuradas en atención a la necesidad de generar cambios al Estado monocultural, excluyente, autoritario y represivo, que no facilita la participación del proceso económico mundial, y en todo caso, debe desarrollar la capacidad de respuesta coherente con los avances de la ciencia y la tecnología y otros temas vitales del nuevo orden social y que en gran medida están siendo determinados por la dinámica económica mundial.

De modo que cuando se analiza el poder, Foucault (citado por Ávila, 2006:217), plantea: “...lo importante es determinar cuáles son sus mecanismos, sus implicaciones, sus relaciones, los distintos dispositivos de poder que se utilizan en los distintos niveles de la sociedad. Una de las interrogantes que Foucault trata de responder es la posibilidad de que el poder pueda deducirse de la economía....". 
El poder y la gerencia en las organizaciones

Bustamante U., Suleima; Pérez de M., Isabel y Maldonado P., Marisabel

Este planteamiento revela que las concepciones sobre el poder giran en varias direcciones, puesto que está considerado como un mecanismo de dominación inherente a la condición humana, para algunos el poder es riqueza, es conocimiento. También es una necesidad implícita en el hombre, expresada en la búsqueda permanente por asociarse para satisfacer sus carencias como ser humano y que tiene su soporte en la concepción de los derechos humanos individuales, derivada de los derechos sociales que en el derecho del trabajo ofrece una particular significación. En consecuencia, el derecho de asociación es un beneficio del hombre y resulta difícil desvincular esta idea del derecho a formar grupos para su libre funcionamiento.

Hobbes (1588-1679) destaca que en principio todos los hombres son iguales, están inmersos en un estado de naturaleza donde existe una guerra de todos contra todos, si dos hombres desean la misma cosa y no pueden obtenerla, ambos se vuelven enemigos y tratarán de aniquilarse; no hay seguridad ni de la propia vida. De igual manera plantea que el único camino seguro a seguir es elegir un hombre o una asamblea que represente su personalidad, a la cual todos deberán someter sus voluntades, se trata de una unidad real constituida por el pacto de cada hombre con los demás.

Para Hobbes el fundamento del poder es llegar a la paz y a la seguridad a través de normas que ellos crearán por mutuo consenso. Destaca que el poder de un hombre consiste en sus medios presentes para obtener algún bien manifiesto futuro, puede ser de carácter origi- nal o instrumental. El poder natural es la eminencia de las facultades del cuerpo o de la inteligencia, así como una fuerza, belleza, prudencia, aptitud, elocuencia, liberalidad o nobleza extraordinaria. El poder instrumental es aquel que se adquiere a través de la fortuna, y sirven como mediose instrumentos para adquirir más, tales como: la riqueza, la reputación, los amigos y los secretos designios de Dios. El mayor de los poderes del hombre es el que se integra con otros hombres unidos por el consentimiento en una persona natural o civil; tal es el poder de un Estado (Hobbes, 2001).

Es imprescindible continuar con las concepciones ampliadas que Hobbes establece sobre el poder, en tanto su ampliación y aplicabilidad a la realidad societal. De allí que la reputación es poder, por cuanto con ella se consigue la adhesión y el afecto de quienes necesitan ser protegidos. También el éxito es poder, por cuanto da reputación, da sabiduría, la nobleza también es una forma de poder.

La forma en que se distribuye el honor social dentro de una comunidad hace surgir un orden social, relacionado con el orden jurídico y económico como forma de distribuir y utilizar los bienes y servicios económicos. Para Weber (18641920) el poder consiste en la probabilidad que tiene un hombre o una agrupación, de imponer su voluntad en una acción comunitaria. La aspiración a tener poder viene motivada por el honor social que este produce. De igual manera distingue el poder político de las otras formas de poder, como el ideológico y el económico, dado por el medio específico a través del cual es ejercido, es decir la coacción físi- 
ca legítima, la amenaza a ejercer coerción en caso de trasgresión al orden, a la norma o al mandato.

Desde este punto de vista cabe distinguir tres tipos de poder: a) el político, quien lo detenta posee los medios de coacción física en forma legítima; b) el económico, está caracterizado por la posesión de bienes y riquezas; c) el ideológico, basado sobre el control de los medios de persuasión, lo que permite actuar o influenciar sobre el pensamiento de los demás; en este sentido, es visto como la capacidad para actuar e influenciar sobre otros seres.

Sin embargo, para Galbraith (1985), existen tres tipos de poder: a) "el poder condigno obtiene la sumisión infligiendo o amenazando consecuencias apropiadamente adversas..."; b) el poder compensatorio, que se define como el dominio que se basa en la recompensa, y se manifiesta en la sumisión a otros, el cual se recubre con una relación contractual o de beneficio mutuo; y c) el poder condicionado, el cual nace del conjunto de creencias y mecanismos de persuasión y depende del manejo de los valores y principios que posee el individuo.

De acuerdo a Gumplowicz y Merton (citado por Briceño, 2000), el poder tiene que ver con las relaciones entre dirigente y dirigido y, por ello, mencionamos algunos tipos, en atención a su materialización: a.) poder político (es la forma de alcanzar el poder en las organizaciones, siendo la más característica la del poder del Estado; b) poder militar (fuerza producto de la capacidad bélica de un Estado; c) poder económico ( medios para lograr los fines del bienestar de la población, capacidad financiera de una organización, generalmente referida al Estado; d) poder social ( poder religioso, poder nacional, poder estatal, legislativo, entre otros).

Rousseau (1982) en su obra el contrato social manifestó que "del poder se origina una obligación, y si se acepta un dominio por fuerza, no es necesario obedecer por deber. Esto sirvió de fundamento a la ideología de la clase burguesa que enfrentaba a una monarquía que era fundamento de una dominación política, contradicción irreconciliable cuando ya dichos señores feudales habían perdido muchos años antes su hegemonía económica. El contrato social, permite una protección y esto implica una organización colectiva donde los individuos participan de esas actividades políticas, pero estaban controlados por la estructura del Estado. Estas ideas, de algún modo, justificaban la causa revolucionaria de la burguesía en el siglo XVIII, aparentaban una libertad económica y política, sólo aprovechable por el capital para luchar contra la nobleza (Velásquez, 2002).

Algunas teorías refieren al poder como una fuerza, a niveles inferiores y más animales, por ejemplo, es mejor hablar de fuerza que de poder. Una presa es tomada por la fuerza y llevada por la fuerza a la boca, cuando la fuerza dura más tiempo se convierte en poder. Sin embargo, en el instante crítico, que llega de pronto, en el instante de la decisión y de lo irrevocable, es otra vez fuerza pura. El poder es visto como más general y más vasto que la fuerza y no es tan dinámico, es más complicado e implica incluso una cierta medida de paciencia; pertenece al poder, en oposición a la fuerza, una cierta ampliación: más espacio y también algo más de tiempo. 
El poder y la gerencia en las organizaciones

Bustamante U., Suleima; Pérez de M., Isabel y Maldonado P., Marisabel

El análisis realizado por Ávila (2006: 225), sobre el concepto de poder en Foucault, destacan dos concepciones, una jurídica y liberal del poder político y otra, la marxista, donde se explicita que la primera tiene que ver con el derecho que se tiene cuando se es poseedor de un bien y puede transferirse o enajenarse, a través de un acto jurídico. Mientras que la concepción marxista, el poder guarda relación con la funcionalidad económica.

Así mismo en este análisis reseñado, para Foucault, el poder no es una propiedad sino una estrategia, y ....además, postula que el Estado no es de ninguna manera, el lugar privilegiado del poder sino que es un efecto de conjunto, por lo que hay que estudiar lo que el llama sus hogares moleculares... Disiente de la afirmación de que el poder debe entenderse como algo intrínseco al aparato del Estado, el cual dependería de un modo de producción que sería su infraestructura".

De modo que el poder lo define el tipo de sistema político, económico, e ideológico, que prevalezca, es decir, sus características estarán dadas por la aplicabilidad de uso que los individuos hagan de este.

El poder visto desde la denominada sociedad de occidente, establece que con el desarrollo de relaciones económicas derivadas de la propiedad de la tierra, se estableció el régimen feudal; y con este se extendió el dominio por parte de los señores dueños de los medios de producción contra los agricultores que trabajaban los terrenos de los grandes propietarios y de los que para ese momento ejercían el poder político, los monarcas. Aquí se observa las relaciones de fuerza de múltiples maneras: el control físico por parte del Estado con base al derecho, el rol protagónico de la institución religiosa (católica); y por la otra la hegemonía física y jurídica de los señores hacia siervos y artesanos (Velásquez, 2002).

También de define el poder como "la probabilidad que tiene un hombre o una agrupación de hombres, de imponer su propia voluntad en una acción comunitaria, inclusive contra la oposición de los demás miembros", destacó al poder como el dominio individual o colectivo establecido por unos con respecto a otros; donde se impone la fuerza, actitud que justificó el poder del estado en la sociedad y su papel de arbitro permanente (Weber, 1992).

Desde esta perspectiva de análisis también es conveniente destacar otras concepciones del poder, si se quiere más generales, entre ellas: a) el poder abierto: considerado como aquel que admite el pluralismo de las aspiraciones colectivas y se adapta constantemente a las modificaciones que se suscitan en los deseos de la colectividad. Es el poder típico de una democracia, donde la crítica es tolerada, y la alternancia en el poder es la principal base de evitar el abuso, la corrupción y sometimiento de unos a otros; b) poder cerrado, definido como aquel que una vez instaurado sobre la base de una representación de la sociedad, que es inmutable, se cristaliza, escapando "en adelante a toda revisión porque la forma en que se ejerce la potestad estatal, hace que esta potestad sea monopolizada por la fuerza política que se erige en dueña del Estado, es el poder típico de las dictaduras en todas sus formas, ya sean civiles o militares, en don de quie- 
nes detentan el poder harán todo lo que sea necesario para perpetuarse en él.

Este análisis da cuenta de que los hombres son libres, iguales e independientes en el estado de naturaleza y señor absoluto de su persona y de sus bienes. Pero son inseguros en ese estado de naturaleza debido a que son atropellados por el resto de los hombres. Por lo tanto se reúnen para renunciar a ese poder natural y entregarlo a la comunidad para obtener así esa seguridad añorada. Así se constituye la sociedad civil o política.

En cuanto a su concentración, el poder se puede referir también como centralizado, que es aquel donde el poder está monopolizado por una sola persona, la misma que, naturalmente delega alguna de sus funciones en otras personas. Mientras que el poder descentralizado es concebido como aquel que se sustenta en autoridades de distinto origen, que responde a su propia base; que depende de sus competencias y de lo que señale la autoridad central. Cada nivel de la autoridad, puede hacer u ordenar hacer una serie de cosas y tomar diversas decisiones y hacerlas cumplir con su propia fuerza en caso de incumplimiento. Al depender de distintas autoridades el poder central ejerce menos presión sobre los gobernados.

Hemos presentado en este apartado la diversidad filosófica que existe sobre la concepción del poder, motivado por el interés de contar previamente con la fundamentación teórica-conceptual, para continuar con la revisión de la otra variable seleccionada en este estudio, como es la gerencia. De modo que, continuamos en el siguiente, con la incidencia y/o aplicabilidad de uso que de éste se hace en las organizaciones y su incidencia en la productividad.

\section{El poder y la gerencia. La dinámica de su vinculación en las organizaciones.}

El poder impone una dinámica que incide en el modo de gerenciar las organizaciones y que guarda relación con la realidad social presente, de hecho, éste no puede ignorarse por cuanto se pierde la oportunidad de llegar a esas realidades y de preparar a los distintos actores de las organizaciones para hacerles frente. El dominio por quiénes ostentan el poder, está implícito en la burocracia de la organización, comprendiendo que el hombre moderno según Michels (2001) se enfrenta al dilema de no poder tener grandes instituciones, tales como estados nacionales, gremios, partidos políticos, ni iglesias, sin ceder el poder efectivo a los pocos que ocupan los cargos superiores de esas instituciones.

Así mismo establece una teoría de la organización y es que éstas crean el monopolio del poder, se refiere en este caso a las organizaciones de gran escala, entre ellas: los partidos políticos, los gremios y las otras organizaciones grandes que tienden a desarrollar una estructura burocrática, es decir, un sistema de organización racional concebido jerárquicamente. Destaca que la administración y su problemática requieren burocracia, y esto guarda relación con el aumento de ésta y la concentración del poder en los estratos más elevados de la organización y la pérdida de influencia en los miembros de número. 
El poder y la gerencia en las organizaciones

Bustamante U., Suleima; Pérez de M., Isabel y Maldonado P., Marisabel

Las organizaciones cuando se hacen más grandes se burocratizan, se especializan y la toma de decisión es cada vez más compleja y ocurre de una forma más rápida. Los propios individuos que saben tratar estos temas complejos con los que se enfrenta la organización se vuelven imprescindibles. Se evidencia una dicotomía entre eficiencia y democracia interna. De allí que cualquier organización para ser eficiente necesita un liderazgo fuerte, a pesar de que esto signifique una menor democracia interna. En tercer lugar, Michels afirma que la propia psicología de las masas hace deseable el liderazgo, pues las masas son apáticas, esperan a que se les resuelvan los problemas, son agradecidas con el líder, y tienden al culto de la personalidad.

En las organizaciones las masas no tienen la fuerza para participar en la toma de decisiones, debe estar apoyada en un liderazgo fuerte. Sin embargo, ocurren desviaciones en la misión y visión organizacional, producto de las necesidades de acceder a los reclamos que se producen en las asociaciones o sindicatos que hacen vida en ellas, que conducen al predominio de subjetividades por parte de la gerencia influenciada por los cambios acelerados en la ciencia, la tecnología, y los consiguientes procesos de ruptura en el orden social, político y económico.

En las organizaciones, especialmente las grandes, guardan relación con los gobiernos al ser fundamentalmente entidades políticas. Sin embargo, las luchas por el poder y por las influencias que afloraban como consecuencia de la interdependencia y la disparidad de criterio, se ven ahora inmersas en un mundo de orga- nizaciones más pequeñas y simples, con menos interdependencia y diversidad interna y por lo tanto, con un carácter menos político. No obstante, que estos cambios estructurales, aunque disminuyen la interdependencia y los conflictos en los senos de las organizaciones, incrementan la dependencia mutua entre ellas.

Así García (1998) plantea que la gerencia puede ser vista como un proceso complejo que depende del liderazgo y la calidad humana de quien la ejerza, que ofrece el poder de incidir en el cambio organizacional y en el mejoramiento constante de la calidad del trabajo.

Obviamente que existe un problema en este enfoque y que tiene que ver con la relación del poder y la gerencia. No puede ignorarse las manifestaciones en este sentido, por cuanto se pierde la oportunidad de llegar a una mejor comprensión de los procesos organizacionales. Entendemos que debe existir la disposición por parte de los miembros de la organización, para aceptar el poder y su uso por la gerencia como una forma de aumentar su productividad. El problema no radica en la falta de agudeza de sus miembros o inteligencia organizativa: es más bien un problema de pasividad (Pfeffer, 1993).

El interés por estudiar el poder y la gerencia, como variables medulares de esta investigación, se basa en el reconocimiento de que las dos forman un eje que moviliza o paraliza la productividad de las organizaciones. Pudiera decirse que la existencia de un equilibrio entre ellas, facilita el cumplimiento de la misión, en cuanto a logro de objetivos, planes, programas y proyectos. Es importante que la gestión en la organización se de bajo una 
distribución equitativa del poder, por cuanto esto incide en la mejora y la trascendencia de sus resultados. El actuar de esta manera conduce hacia la asociatividad, la cual tiene que ver con la capacidad de generar formas de cooperación y de sinergias permanentes. La organización donde prevalezca un clima de armonía caracterizado por el trabajo cooperativo, de suma de esfuerzos, estará abierto a la búsqueda constante del cambio, de la creatividad y de la innovación de la organización en su conjunto.

Al contrario, cuando una organización no posee las competencias para lograr el trabajo sinérgico, bajo las mas elementales normas de convivencia, no podrá dar la solución a sus problemas colectivos y termina haciéndose cuestionamiento no solo a la persona que ocupa un cargo gerencial, que de hecho, detenta el poder, sino que la responsabilidad de los conflictos o desavenencias se van acentuando y los demás integrantes de la organización pasan a tener su cuota de corresponsabilidad, y en consecuencia se deteriora el trabajo en equipo y el rendimiento será cada vez menor.

Obviamente cuando se generan situaciones de esta naturaleza, la búsqueda del equilibrio y la armonía organizacional no es fácil, sin embargo, todo gerente debe ser incansable en la búsqueda de metodologías que induzcan el desarrollo de procesos para la mejora continua, y la generación de sinergias en su organización, que no sea el poder el factor perturbador para cumplir con la responsabilidad y el compromiso que le corresponde. La calidad de gestión se evaluará, por el incremento de la participación de sus miembros, por la mejora de la imagen corporativa. Pudiera decirse que "el buen uso del poder" se manifiesta en la capacidad para alimentar el sentido de filiación, donde se evidencie implícita y explícitamente la conveniencia de combinar una arraigada identidad corporativa con una capacidad gerencial y técnica (Bustamante, 1997); obviamente que la relación gerencia y poder, bien vista, está dada por el desarrollo deontológico que guarda relación con el desarrollo de conductas marcadas por los deberes frente a la organización y al entorno.

En estos planteamientos hechos hasta ahora, ¿dónde queda el liderazgo y la ética? destacamos que la dinámica gerencial, necesariamente implica el condicionamiento para desarrollar el liderazgo personal y grupal, en correspondencia con los derechos humanos, de modo que, la democracia constituye un valor en la organización. Rivadeneyra (2001) destaca que las teorias sobre democracia no son expresiones realistas de la historia sino formas de interpretar el mundo, reflexiones acerca del poder, de su uso y abuso, de sus limitaciones legales orientadas al mantenimiento del poder.

En cuanto a la ética, pudiera decirse que es un componente decisivo de la dinámica entre el poder y la gerencia. Por cuanto los valores éticos...

....son constructivos pro desarrollo, pro crecimiento compartido, pro justicia social, pro progreso tecnológico, pro reglas limpias de juego, pro transparencia en el manejo de la gestión publica y de la gestión privada.... (Kliksberg, p.18).

Así mismo encontramos casos donde la actividad desarrollada por el gerente se caracteriza por la falta de conocimiento de la realidad organizacional y, 
El poder y la gerencia en las organizaciones

Bustamante U., Suleima; Pérez de M., Isabel y Maldonado P., Marisabel

esto es impedimento para la toma de decisiones asertivas, donde prevalezca el respeto a la individualidad y al grupo. También juega papel importante el liderazgo, en tanto una forma inductora de la cooperación de las personas, implica desarrollar la en los miembros de la organización su compromiso para el logro de los objetivos comunes, que se conviertan en interventores organizacionales para la resolución de conflictos, bajo cánones compartidos, clima organizacional de amplitud, que exista la comunicación permanente, todo esto supone la existencia de una base fundamentada en la confianza ${ }^{1}$. Las organizaciones están en constante aprendizaje y ello se traduce en la forma de organizarse o en los cambios de estructura; por supuesto que esto abre el camino a nuevas posibilidades y nuevas formas de vencer barreras; en tanto que, el aprendizaje es acción en sí misma y que requiere de competencias propias. La confianza constituye un factor crítico en el proceso de aprendizaje y de productividad organizacional, donde la gerencia y el poder son aspectos que marchan juntos, Echeverría (2000) destaca que:

"La confianza es la emocionalidad clave del nuevo modo de hacer empresa. Con confianza el trabajador se abre al aprendizaje, se atreve a innovar, acepta cometer errores y confrontar sus ignorancias e incompetencias (p.91).
De modo que es necesaria la existencia del diálogo para una interrelación satisfactoria entre la generación y transferencia de ideas, por cuanto viabiliza el intercambio de quienes disponen de las competencias para la generación de posibilidades y oportunidades, elemento importante para hacer uso del poder y gerenciar con eficiencia. La efectividad en la toma de decisiones por parte de la gerencia, guarda estrecha vinculación con el grado de poder y la aplicabilidad de uso que se le de, desde el punto de vista de los criterios de autonomía o imposición que prevalezcan.

...una relación sustentada en la confianza no es necesariamente una relación entre iguales...., el fundamento del poder es diferente en las relaciones sustentadas en la confianza, el poder se ejerce por autoridad y no recurriendo a la fuerza (Echeverría, 2000: 109).

Un resultado observable del buen uso del poder por parte del gerente está asociado a la calidad de las conversaciones que se desarrollan en la organización, pues la conversación es la principal herramienta de los directivos, por cuanto su relación con sus colaboradores y con sus clientes se materializa en la conversación; esta supone más que la comunicación, vista como la interacción en un contexto; la conversación supone que la comunicación se de y avance por diferentes contextos con espíritu generativo; es

1 La confianza permite el desarrollo de acciones transformadoras, capaces de generar y conquistar nuevos mundos, futuro y posibilidades. Se trata de acciones de invención e innovación, sustenta las acciones creativas, de los descubrimientos tecnológicos, de las grandes transformaciones políticas y culturales, alimenta el espíritu emprendedor Puede ser vista tanto como un atributo de los actores o atributo de la estructura del sistema dentro del cual esos actores operan (Echeverría, 2000: 119). 
decir creando nuevas visiones, nuevas oportunidades sobre el mismo asunto (Senge, 1990; Echeverría, 2000).

¿Cómo nos damos cuenta de nuestra influencia como gerente? ¿Sí está orientada positiva o negativamente? Una respuesta podría ser, observando nuestros logros a partir de las conversaciones. Podríamos decir si en lugar de generar confianza, producimos tensiones y alarmas, en vez de solucionar problemas, creamos nuevos; y si cuando es necesario lograr converger conseguimos divergir.

Así también encontramos en esta interpretación que hacemos de la dinámica del poder y la gerencia, infinidad de experiencias vividas diariamente por mucho de nosotros, miembros de organizaciones universitarias y, que están muy cercanas con lo que pudiera denominarse "la doble cara del poder" por cuanto observamos una excesiva centralización, donde la política de recursos humanos es más bien descendente y no ascendente, no permite la participación de sus miembros en las decisiones más simples y menos aún en las transcendentales, ¿por qué esto? La explicación, desde nuestro punto de vista, es que todo tiene un matiz político; de hecho, se evidencia en el contexto de las universidades que cuentan con recurso humano de primera y que constituye su capital humano y capital social, sin embargo, no son tomados en cuenta en la programación y en la ejecución de los programas y proyectos institucionales.

Esta situación muchas veces está dada por la falta de confianza en la gente, suponemos entre gerentes y subgerentes, entre directores y empleados, todo esto cierra posibilidades, restringe las relacio- nes. Luhmann (1996) refiere que la confianza tiene el efecto de reducir tanto la incertidumbre como la complejidad, lleva a generar acciones transformadoras e innovadoras y genera nuevas posibilidades.

Existen organizaciones donde la rigidez caracteriza a la gerencia, que se perfila más a la necesidad de mantenerse en el poder lo que impide desarrollar la capacidad para solicitar y obtener ayuda, por temores ocultos a reconocer su incompetencia.

Así mismo encontramos en las organizaciones gerentes que no rinden cuentas o les molesta hacerlo, cuando es su obligación presentarlas, por cuanto es el uso del patrimonio de la organización, entonces ¿cómo queda el proceso de mejora continua a través de la implementación de los mecanismos organizacionales de control y evaluación de la gestión, que mide el desempeño para generar un mayor grado de responsabilidad? ¿Cuáles son los criterios e indicadores utilizados para evaluar la calidad de gestión? Pareciera que existiera un temor por parte de las direcciones y/o unidades creadas para tal fin, para enfrentar o controlar a los que ocupan, circunstancialmente, los "cargos con poder".

Desde esta perspectiva de análisis, nuestra experiencia en el ámbito universitario, da cuenta de ejemplos en este orden, al respecto Díaz (2005:4) destaca que emergen realidades como estas ...: (a) muchas veces se siente más compromiso con las personas que con la organización; (b) en algunos casos las autoridades no concentran su pensamiento en ejecutorias concretas y en conformar equipos con compromiso institucional; $y$ 
El poder y la gerencia en las organizaciones

Bustamante U., Suleima; Pérez de M., Isabel y Maldonado P., Marisabel

por el contrario la gestión transcurre en acciones orientadas a permanecer en cargos directivos marcadas más por una expresión del poder, por el poder mismo que por una vocación de servicio y (c) en consecuencia esta realidad que registra la historia de los últimos años nos hace ver que, en muchos casos, es más importante un voto que una idea.

Estamos claros que la autoridad es un poder, que cada uno de nosotros como miembros de una organización conferimos; de acuerdo con Echeverría, otorgamos autoridad cuando hay confianza, de lo contrario no confiamos en el jefe y dejamos de conferirle autoridad, así esté en la cúspide de la pirámide.

La calidad gerencial se evalúa a través de la capacidad para detectar desafíos, oportunidades, y formular objetivos claros y cumplirlos. Para ello se necesita la supervisión permanente al conjunto de tareas individuales para asegurar el logro de esos objetivos. La gerencia desarrollada sobre la base de la transferencia de información y de comunicación oportuna de los planes, programas y proyectos, constituiría la base para hacer una eficiente distribución de poder, no solo porque diversificaría las tareas a desarrollar, sino también porque faculta para la toma de decisiones en tanto que, fundamenta la interacción social, se descubre potencialidades, fomenta el trabajo en equipo y esto coadyuva con los procesos de cambio para la productividad en todos los ordenes, además que permite explorar, experimentar e innovar.

Diremos entonces que, la gerencia de hoy debe perfilarse más al desarrollo de la capacidad de obtener ayuda que a la obtención y permanencia en el poder.
Esta forma de enfocar la gerencia estará acompañada con acciones complementarias y de apoyo para el fortalecimiento individual y/ organizacional; es decir, el énfasis de la gerencia deberá estar centrada a una gestión de resultados, la cual involucra una gestión de procesos, y no en un control de acciones.

De igual manera, existe otro elemento a reseñar en este estudio, como es la comunicación, en tanto elemento crítico en el equilibrio organizacional, de hecho, su presencia es vital, por cuanto ayuda a enfrentar "el mal uso del poder" y para ello es necesario el diseño de sistemas de información y comunicación gerencial, en este orden Peñalver (2004:42) destaca que: ....la comunicación puede ayudar a enfrentar la cultura de la destrucción! La universidad puede constituirse en un espacio para la comunicación, para el debate con respeto; para hacerle muro a la intolerancia, a las acentuadas diferencias, a la cultura del despilfarro de la palabra.

Resulta claro que la comunicación se traduce en apertura para el aprovechamiento sistemático de la producción organizacional, por lo tanto es necesaria la estructuración de sistemas de información gerencial que se comporten como mecanismos de crecimiento de la organización, y por supuesto, esto facilitaría, como ya lo anotamos antes, hacer una mejor distribución del poder. Pfeffer (1993) plantea la existencia de una marcada ambivalencia sobre el poder, y afirma que los conceptos de la pugna gerencial y el poder están estrechamente vinculados, en algunos casos, permite logros en la organización y en otros casos no. De modo que el poder se constituye en factor crítico-clave para una efecti- 
va conducta gerencial, el cual debe ser aplicado como alternativas de solución para la gestión, la innovación y la competitividad.

La interdependencia es otro elemento a considerar en el uso del poder, una vez que ésta es definida a partir de la existencia de agentes interdependientes, y esta existe siempre que el sujeto activo no posea el control de las acciones para la obtención de resultados determinados. Es satisfactoria por cuanto facilita el trabajo en equipo, y esta ocurre de la forma en como se da la organización de las acciones y de igual modo, por la escasez de recursos.

En la actividad gerencial no siempre interviene el poder en las decisiones que se toman; tampoco en todas existen conflictos de poder. Lo importante para que la dinámica gerencial y el poder faciliten la fluidez organizacional, es la existencia de relaciones de interdependencia entre los miembros, por cuanto permite la creación de las comunidades de aprendizaje, que descubren las potencialidades y la generación y transferencia de conocimiento simultánea.

Nos han acostumbrado a la profunda asimetría del poder entre el jefe y el trabajador y, que por consiguiente incide notoriamente en las relaciones entre ellos. Así también acostumbrados a observar que el poder se concentra en la cúspide de la pirámide, sin embargo; si se invierte la pirámide se haría una mejor distribución de la responsabilidad y el compromiso, por cuanto este aumentaría y pudiera generarse mayor disposición de los niveles de mayor jerarquía (Echeverría, 2000: 93).
Es importante la estructura organizativa, donde exista una horizontalidad funcional, se generará un clima de mayor confianza y comunicación entre sus miembros, lo cual se reflejará en una mayor productividad.

\section{Conclusiones}

Una vez hecha esta disertación del poder sobre la base filosófica de su concepción, observamos que éste y la gerencia se constituyen en factores del éxito o fracaso organizacional, dependiendo de la aplicabilidad de uso que se implemente; esto permite destacar algunos puntos, tales como:

Es imprescindible el equilibrio entre el poder y la gerencia a partir de la distribución equitativa del primero, por cuanto esto motiva a los miembros de la organización, generando: participación, cambios y mejoras.

La discusión, análisis e interpretación de las variables poder y gerencia, permitió apreciar la notoria ambivalencia acerca del poder, donde encontramos por ejemplo que, el poder centralizado genera distanciamiento entre los miembros de una organización, afectando la iniciativa y la emocionalidad del individuo la cual se traduce en la baja producción, la acumulación de tareas y poca motivación para generar cambios; mientras que la distribución equitativa del poder crea el contexto para la gestión de calidad en las organizaciones, por cuanto incide en el compromiso de cada uno de los integrantes.

Así mismo, el poder visto desde el actuar del gerente y el directivo, esta implícita y explícitamente vinculado a las 
El poder y la gerencia en las organizaciones

Bustamante U., Suleima; Pérez de M., Isabel y Maldonado P., Marisabel

estructuras organizativas que también son fuentes de poder. En algunos casos, una determinada posición jerárquica en la estructura, puede ser un medio permisible para la obtención de información y eso otorga poder. Además, la estructura de una organización sea funcional o matricial, facilita la implementación de estrategias para el ejercicio del poder, y la asignación de responsabilidades.

En este sentido, podemos afirmar que la mayoría de las estructuras organizativas han sido diseñadas para otorgar poder a la vez que son utilizadas para mantener el poder político.

La gestión de calidad está caracterizada por el liderazgo, la comunicación y la confianza, la ética y los valores, cada uno de ellos se comportan en factor clave en la productividad organizacional. De modo que la gestión, debe girar en torno a la autonomía responsable y la transparencia a la hora de rendir cuentas.

Esta reflexión nos da cuenta de que el poder y la gerencia tienen mucho que ver con los rasgos personales de la gente, la moral, los valores y la ética.

\section{Referencias Bibliográficas}

Ávila-Fuenmayor, Francisco (2006). "El concepto de poder en Michel Foucault". Revista Telos. Vol. 8 No 2. pp. 215234. Universidad Dr. Rafael Belloso Chacín, Maracaibo, Edo Zulia.

Briceño García, Jesús (2000). Liderazgo Integral para el Progreso. Caracas, Venezuela.

Bustamante, Suleima (1997). Contribución teórico-metodológica al estudio de la capacidad innovativa en organizaciones de educación superior. Trabajo de ascenso para optar a la categoría de Profesor Titular. UPEL-IMPM, Caracas, Venezuela.

Díaz Quero, Víctor (2006). Palabras con motivo del acto de reconocimiento de los docentes-investigadores acreditados en el programa de Promoción del Investigador (PPI) UPEL- IMPM, Caracas, 12 de junio. Venezuela.

Echeverría, Rafael (2000). La empresa emergente, la confianza y los desafíos de la transformación. Ediciones Granica S.A. Buenos Aires, Argentina.

Galbraith, John (1985). La anatomía del poder. Plaza \& Janes, editores, Madrid, España.

García García, Blanquita (1998). Educación, Investigación y Gerencia para una mejor calidad de vida: Universidad y Sector Productivo. Trabajo de ascenso para optar a la categoría de Profesor Asociado. Universidad del Zulia, Núcleo Punto Fijo.

García-Pelayo, M. (1987). Las transformaciones del Estado Contemporáneo, 2da edición. Alianza Editorial, Madrid.

Hobbes, Thomas (2001). Leviatan o la Materia, Forma y Poder de una República Eclesiástica y Civil. Fondo de Cultura Económica. México. DF. México.

Kliksberg, Bernardo (2001). El Capital Social. Universidad Metropolitana Edit Panapo. Caracas.

Luhmann, Niklas (1996). Confianza, Ediciones, Anthropos, Barcelona

Michels, Robert (2001). Los partidos políti$\cos 1$. Un estudio sociológico de las tendencias oligárquicas de la democracia moderna. Amorrortu editores, Buenos Aires.

Michels, Robert (2006). Disponible en http:// es.Wilipedia.org/wiki tomado el 23 de nov 2006.

Pfeffer, Jeffrey (1993). El poder en las organizaciones. Política e influencia en una 
empresa. Editorial, Serie Mc GrawHill de Management. Madrid, España.

Peñalver, Luís (2004). Pensar la universidad en el siglo XXI. Revista. La Universidad se Reforma II. Revista Colección Debate sobre la Reforma, Universidad Central de Venezuela.

Rivadeneyra, Jorge (2001). El Señorío de la Democracia. Revista Intento (1). 77-94. FACES, UCV. Caracas.

Rousseau (1982). El contrato social.
Senge, Meter (1990). La Quinta Disciplina. EI arte y la práctica de la organización abierta al aprendizaje. Edit, Granica, México.

Velásquez Márquez, Alvaro (2002). "Reflexiones históricas sobre el poder". Revista Fontus, editada por la Asociación de Profesores de la Universidad de Oriente, Cumaná, Venezuela.

Weber, Max (1992). Economía y Política, Tomo II, Fondo de Cultura Económica, México. D. F. México. 